\title{
Experimental and numerical study on the performance of solar walls in Mediterranean climates
}

\author{
Francesca Stazi ${ }^{1}$, Alessio Mastrucci ${ }^{1,}{ }^{,}$, Costanzo Di Perna ${ }^{2}$ \\ ${ }^{1}$ Dipartimento di architettura, costruzioni e strutture (DACS), Facoltà di Ingegneria, \\ Università Politecnica delle Marche, Via Brecce Bianche, 60131 Ancona, Italy \\ 2 Dipartimento di energetica, Facoltà di Ingegneria, Università Politecnica delle Marche, \\ Via Brecce Bianche, 60131 Ancona, Italy \\ *Corresponding author.Tel: +39 3491604465,E-mail: alessiomastrucci@gmail.com
}

\begin{abstract}
This article focuses on the behavior of an accommodation with Trombe walls in a Mediterranean climate, in terms of energy savings and comfort during wintertime and summertime.

The aims of this study are to identify experimentally temperatures and heat fluxes of the solar wall; compare the solar wall's behavior with a traditional wall from the point of view of consumptions and comfort; optimize the wall in relation to energy savings. In order to do that, various activities were carried out: a series of monitoring activities for several years in different seasons (in this paper only the results obtained for winter and autumn are reported); dynamic simulations with software EnergyPlus on a virtual model calibrated by comparison with experimental results; parametric analyses for the optimization of the wall.

The results demonstrated that solar wall is an efficient system in temperate climates, with an energy savings of $12,2 \%$ and summer comfort comparable to that provided by traditional housing. Finally it was possible to identify optimal design features (Thickness of the wall, absorbance, type of glass).
\end{abstract}

Keywords: Trombe walls, Building envelope, Thermal comfort, Monitoring, Parametric analyses.

\section{Nomenclature}

s component thickness.....

..cm

$U$ thermal transmittance..................W/ $\mathrm{m}^{2} \mathrm{~K}$

$Y_{m n}$ periodic thermal transmittance ....... W/ $\mathrm{m}^{2} \mathrm{~K}$

$f_{d}$ decrement factor ..................................... -

$\varphi \quad$ time shift .............................................. $h$

$T_{\text {out }}$ outdoor air temperature ....................... ${ }^{\circ} \mathrm{C}$

$T_{\text {s,ext }}$ external surface temperature................. ${ }^{\circ} \mathrm{C}$
$T_{\text {s,int }}$ internal surface temperature ................. ${ }^{\circ} \mathrm{C}$

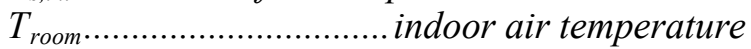

$T_{o p}$ indoor operative temperature................ ${ }^{\circ} \mathrm{C}$

$F_{\text {solar glob hor horizontal global solar radiation }}$

.................................................. W/m

$F_{\text {int }}$ internal surface heat flux density ......W W/ $\mathrm{m}^{2}$

\section{Introduction}

The recent European Directives on the energy performance of buildings established a common direction for the reduction of buildings energy consumptions. Consequently the Member States set up a series of minimum requirements and made it n ecessary to achieve high building envelope performances. Solar passive systems can give a significant contribution to achieve these performances and they may help to save energy both for winter heating and for summer cooling. However there are still few studies in literature on the behavior of solar passive systems, especially on solar walls, in summer [1, 2], on de sign recommendations [3, 4, 5], on comfort conditions produced [6], in Mediterranean climates and in well-insulated envelopes required by national regulations.

Solar wall is a passive solar system used to store heat and transfer it inside the building. It is generally made of a concrete or masonry wall painted black, an air layer and glazing on the exterior. Trombe wall is a particular type of solar wall equipped with vents for the air circulation. Precedent studies [7, 8], focusing on the mode of use of Trombe walls, highlighted that recirculation vents determine consistent heat losses during the cold season and problems of powder rising. For this reason this study focuses on unvented solar walls. 
The objectives of the study are: the assessment of solar walls' effects on energy consumptions and indoor comfort of residential buildings; the development of design recommendations for solar walls in a Mediterranean climate. The methodology used comprehends experimental and analytical activities: a series of monitoring activities on a case study to collect data related to the thermal behavior of solar walls; numerical simulations in dynamic conditions on a model calibrated by comparison with the experimental data; simulations and parametric analyses to extend the results.

\section{Case study}

The case study is a residential building in Ancona, central Italy, and it was built in 1983 to test many passive solar systems. The building includes nine flats on three floors, each equipped with a different passive solar system on the south-facing wall (Fig. 1). The house has a compact shape and it is oriented along the E-W axis in order to maximize solar supply.

The research focused on the accommodation with Trombe walls (Fig. 2), that resulted from precedent studies [7] the best solar system among the ones in the house. The system is made up of a $40 \mathrm{~cm}$ concrete wall painted black, a $10 \mathrm{~cm}$ air layer and glazing on the exterior. Adjustable vents are placed on the top and on the bottom of the wall and on the top of the external glazing to activate ventilation. Roller shutters and horizontal overhangs provide solar radiation control. The configuration of solar wall considered in this study is: ventilation not active (closed vents); movable shading open in winter and middle seasons, closed in summer.

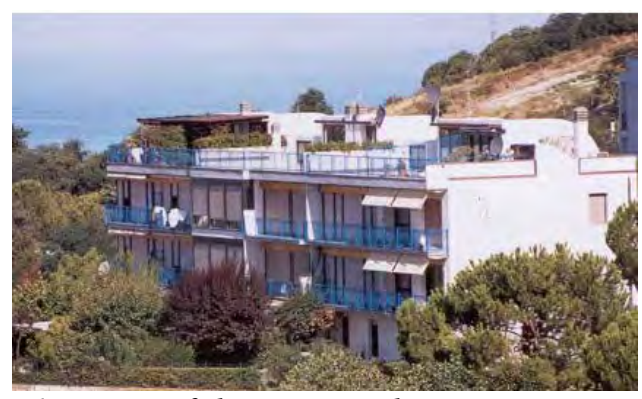

Fig. 1. View of the case study.

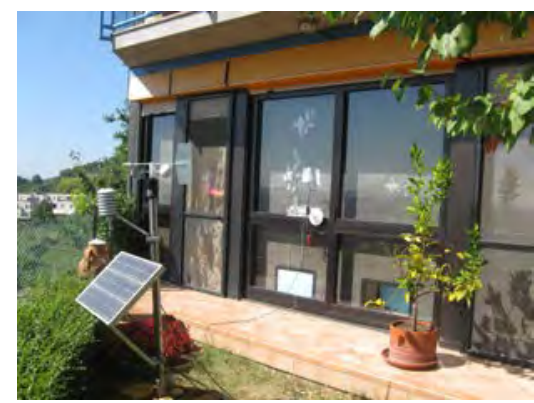

Fig. 2. External view of Trombe wall.

\section{Methodology}

The research consisted of experimental activities in autumn and winter and analytical activities to extend the study to other periods.

\subsection{Experimental activities}

Monitoring activities in the case study were performed for several years in different seasons. In this paper we report only a part of the data measured, regarding these periods:

- Autumn monitoring: $12^{\text {th }}$ October $2007-21^{\text {st }}$ October 2007

- Winter monitoring: $20^{\text {th }}$ December $2008-7^{\text {th }}$ January 2009

Trombe walls were used with closed vents during experiments to reproduce unvented solar walls. Heating system was off during autumn monitoring, while it was switched on in winter with set point $20^{\circ} \mathrm{C}$ and program: 1:30-3:30, 7:30-9:30, 17:30-21:30.

Experimental set-up is described in Fig. 3 and Fig. 4. Data loggers and different types of probes were used to carry out the following investigations: survey of the outdoor climate conditions using an external weather station that included hydro-thermal probe, wind speed 
and direction probe, solar radiation probes (Fig. 5); survey of indoor environmental conditions using indoor microclimate stations with hydro-thermal probe and black-globe temperature probe (Fig.6); detailed thermal survey of Trombe wall using a set of thermo-resistances to measure internal and external surface temperatures and heat flux sensors (Fig.7). External probes were screened from direct solar radiation to avoid values alteration.

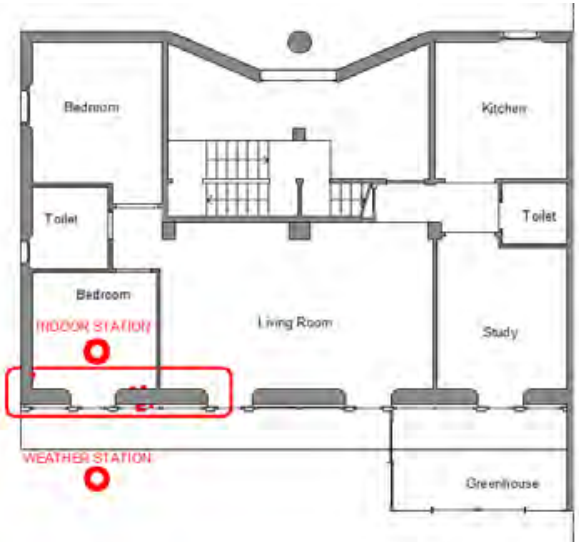

Fig. 3. Experimental set-up: plan of the house

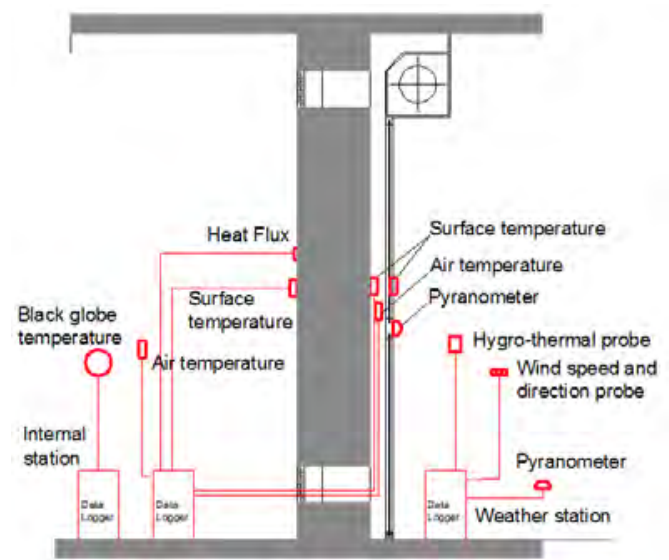

Fig. 4. Experimental set-up: vertical section of Trombe wall indicating the position of probes.

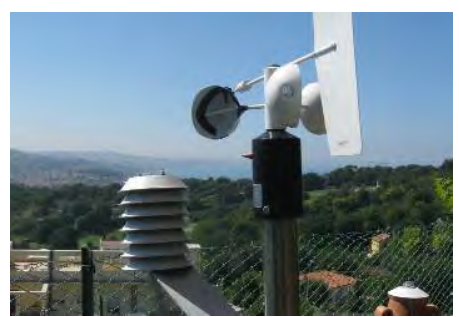

Fig. 5. View of weather station.

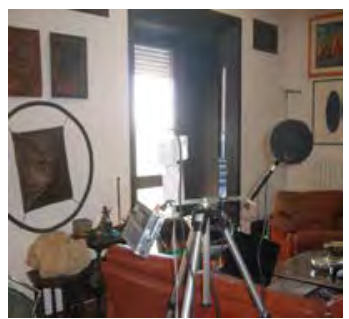

Fig. 6. View of indoor microclimate station.

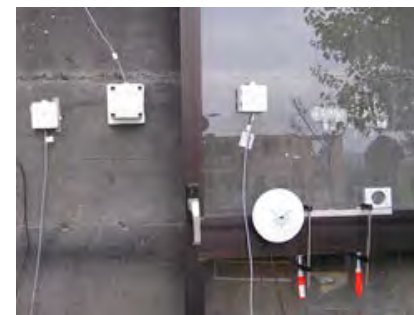

Fig. 7. View of the probes on the outside face of Trombe wall.

\subsection{Analytical activities}

Numerical simulations were performed in dynamic state using software EnergyPlus. Trombe walls can be modeled in EnergyPlus using the algorithm "TrombeWall" validated BY ELLIS [9].

\subsubsection{Model inputs and comparison with experimental data}

Data collected during experimental activities were used as inputs for the model in order to reproduce the real conditions: we developed a climatic input file containing the outdoor conditions measured during experiments, then we defined programs regarding the real users profiles for the building (occupancy, air ventilation, heating system program and set point). The values obtained by calculations were compared with data collected during experimental activities in order to verify the reliability of the simulation tools in reproducing real situations. Indoor air temperatures, surface temperatures and the heat fluxes of the trombe wall were compared. Once the model had been calibrated, it $\mathrm{w}$ as possible to generalize the results running the calculation for a whole year and setting standard input data for the model, according to national reference UNI/TS 11300:2008. 


\subsubsection{Analytical studies on solar walls}

Numerical simulations were performed all over the heating season $\left(1^{\text {st }}\right.$ November to $15^{\text {th }}$ April in Ancona, according to national requirements) in order to determine the thermal behavior of solar walls. Total energy contribution, defined as the difference between solar gains and heat losses through the wall, was used to evaluate the performance of solar wall compared to a traditional one, with the characteristics in Table 1.

Table 1. Thermal characteristics of solar wall and traditional wall according to ISO 13786:2007.

\begin{tabular}{cccccc}
\hline Type of wall & $\begin{array}{c}\mathrm{s} \\
(\mathrm{cm})\end{array}$ & $\begin{array}{c}\mathrm{U} \\
\left(\mathrm{W} / \mathrm{m}^{2} \mathrm{~K}\right)\end{array}$ & $\begin{array}{c}|\mathrm{Ymn}| \\
\left(\mathrm{W} / \mathrm{m}^{2} \mathrm{~K}\right)\end{array}$ & $\begin{array}{c}\mathrm{fd} \\
(-)\end{array}$ & $\begin{array}{c}\varphi \\
(\mathrm{h})\end{array}$ \\
\hline Solar wall & 51,4 & 2,267 & 0,12 & 0,10 & 12,48 \\
Traditional wall & 34,5 & 0,343 & 0,12 & 0,54 & 6,83 \\
\hline
\end{tabular}

\subsubsection{Analytical studies on building envelopes with solar walls}

In order to assess how solar walls can contribute to the performances of a building complying with current energy regulations, the insulation level of envelope components of the case study (except solar walls) was varied to meet national requirements. Then the energy performance of the same accommodation was calculated varying the type of south-facing wall between solar wall and traditional wall, defined above, to assess the energy efficiency of solar wall in comparison with the traditional one.

Indoor thermal comfort analyses were performed to assess indoor quality. Thermal comfort conditions were estimated for the whole year with simulations. PMV method, according to UNI EN ISO 7730:2006 and UNI EN 15251:2008, was applied in winter when the heating system is on. PMVe method [10] was applied in summer (with coefficient $e=0,7$ ) with the hypothesis that the cooling system is not present. Category II, according to UNI EN 15251:2008, was assumed in the assessment of comfort limits.

\subsubsection{Parametric study on solar wall characteristics}

A parametric study was performed using the level factorial plan technique [5]. With this technique it is possible to calculate the effect of variations of single parameters and combinations of parameters on a given phenomenon. The parameters listed in table 2 were chosen. For each of the eight combinations of parameters in Table 3 a simulation was run to determine the effects of variations on the seasonal energy needs for heating of the house.

Table 2. Parametric analyses on the solar wall system.

\begin{tabular}{cccc}
\hline Parameters & Designation & Minimum value & Maximum value \\
\hline Storage wall thickness $(\mathrm{cm})$ & X1 & 30 & 40 \\
Absorbance & X2 & 0,85 & 0,90 \\
Type of glazing & X3 & Single glass (SG) & Double glass (DG) \\
\hline
\end{tabular}

Table 3. Combinations of parameters.

\begin{tabular}{ccccccccc}
\hline Parameters & 1 & 2 & 3 & 4 & 5 & 6 & 7 & 8 \\
\hline X1 & 30 & 40 & 30 & 40 & 30 & 40 & 30 & 40 \\
X2 & 0,85 & 0,85 & 0,90 & 0,90 & 0,85 & 0,85 & 0,90 & 0,90 \\
X3 & SG & SG & SG & SG & DG & DG & DG & DG \\
\hline
\end{tabular}




\section{Results}

\subsection{Results of experimental activities}

Monitoring activities allowed the assessment of the thermal behavior of solar walls in different conditions and periods.

\subsubsection{Autumn monitoring}

Data measured during three typical sunny days in October are reported in Fig. 8 and Fig. 9. On sunny days the wall reaches temperatures over $50^{\circ} \mathrm{C}$ on the external surface. Internal surface reaches temperature peaks during nighttime, with a time shift of about 10 hours, and maintains an average temperature of $23,6^{\circ} \mathrm{C}$. Internal surface temperature is higher than room temperature all time, consequently heat flux is directed from the wall to the room and determines a daily heat gain of $0,95 \mathrm{MJ} / \mathrm{m}^{2}$. It can be noticed that heat flux is higher during nighttime, when the difference between surface and air temperature is higher. This contributes to maintain a constant temperature of about $20^{\circ} \mathrm{C}$ inside the room, with benefits for thermal comfort.

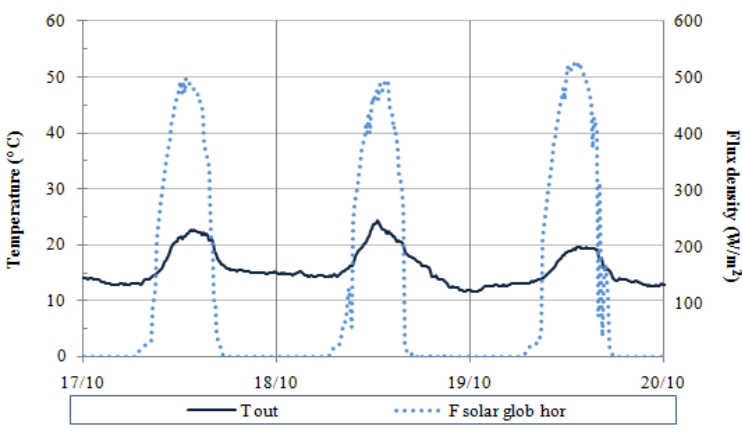

Fig. 8. Climatic data.

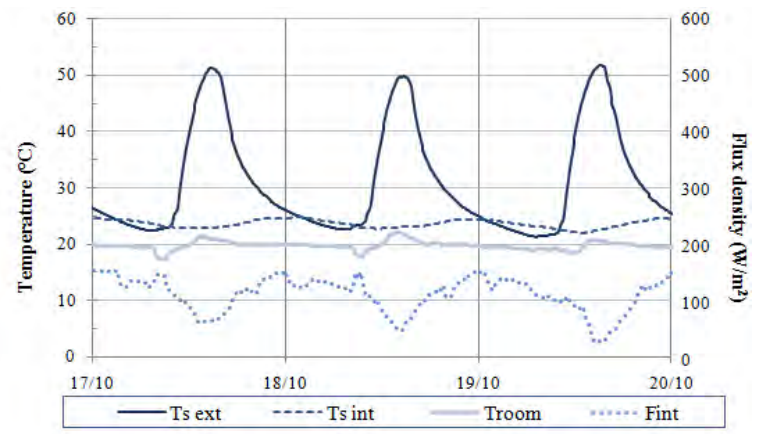

Fig. 9. Temperatures and heat fluxes of Trombe wall and temperature of the room.

\subsubsection{Winter monitoring}

Fig.10 and Fig. 11 show the results of monitoring during three winter days, the first sunny, the second cloudy the third sunny again. On sunny days external surface temperatures can get up to $35-40^{\circ} \mathrm{C}$, while on cloudy days the temperatures are not far from outside air temperature. After a sunny day, internal surface temperatures remain higher than room temperatures and heat flux is directed toward the room, with daily heat gains of $0,45 \mathrm{MJ} / \mathrm{m}^{2}$. On cloudy days internal surface temperatures are lower than room temperatures and this fact causes the inversion of heat flux, from the room to the wall, and daily heat losses of $0,54 \mathrm{MJ} \mathrm{m}^{2}$.

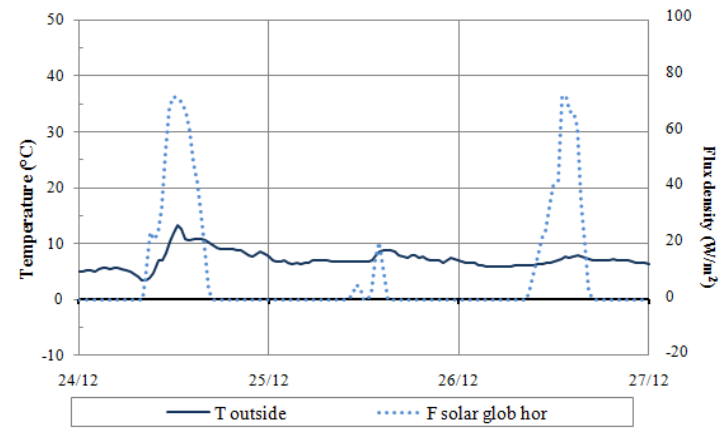

Fig 10. Climatic data.

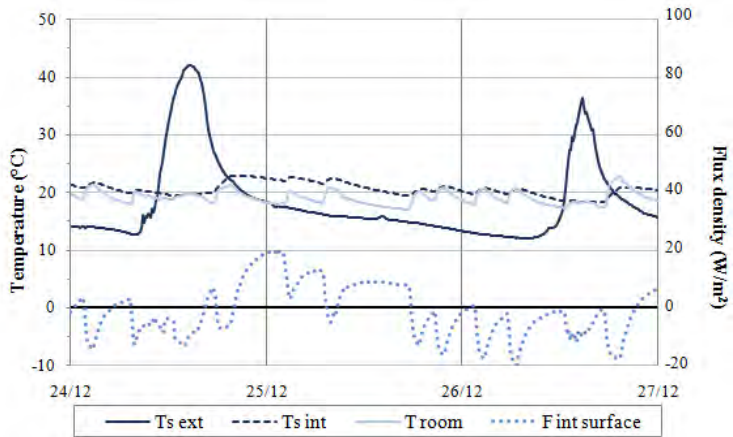

Fig. 11. Temperatures and heat fluxes of Trombe wall and temperature of the room. 


\subsection{Results of analytical activities}

\subsubsection{Comparison with experimental data}

The comparison demonstrated a good agreement between experimental data and simulated data. Fig. 12 shows the results of surface temperatures comparison, the same analysis was performed for heat fluxes. Deviations for internal surface temperatures and heat flux densities are lower than 5\%. Deviations for external surface temperatures are around $10 \%$.
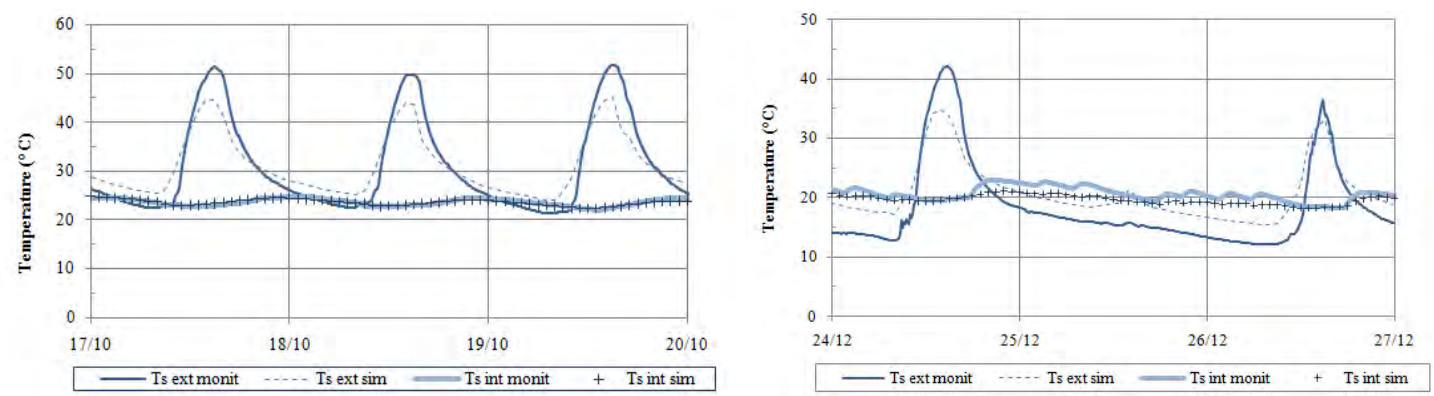

Fig. 12. Comparison of surface temperatures measured and calculated in autumn and winter.

\subsubsection{Energy performance of solar walls}

Total energy contribution was used to compare the performances of solar and traditional wall in winter (Fig. 13) and in summer (Fig. 14).

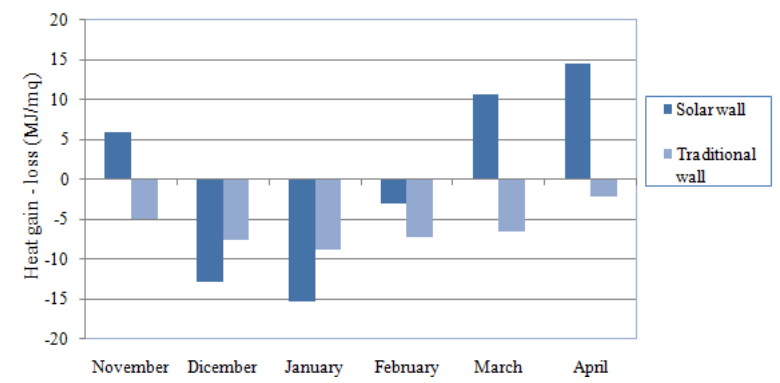

Fig. 13. Total energy contribution of solar wall and traditional wall in winter.

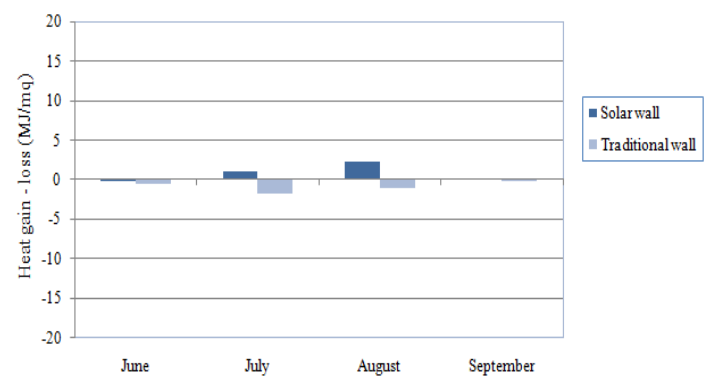

Fig. 14. Total energy contribution of solar wall and traditional wall in summer.

Solar wall's heat losses are higher in the coldest months, due to the high transmittance, but these losses are balanced in other months when solar gains are higher. Considering the whole heating season, traditional wall disperses $37,29 \mathrm{MJ} / \mathrm{m}^{2}$ while solar wall disperses $0,20 \mathrm{MJ} / \mathrm{m}^{2}$. In summer solar wall, even if shaded from solar radiation, behaves worse than traditional wall, because the high transmittance determines higher unwanted heat gains. Considering the whole summer season, solar wall produces heat gains equal to $3,21 \mathrm{MJ} / \mathrm{m}^{2}$, while traditional wall determine heat losses equal to $-3,47 \mathrm{MJ} / \mathrm{m}^{2}$.

\subsubsection{Energy performance of building envelope with solar walls}

Energy analysis confirmed that the house with solar walls has a saving of $12,2 \%$ in heating energy needs compared to the house with traditional walls (Fig. 15). The energy saving is $0,46 \%$ for each square meter of surface of solar wall. 


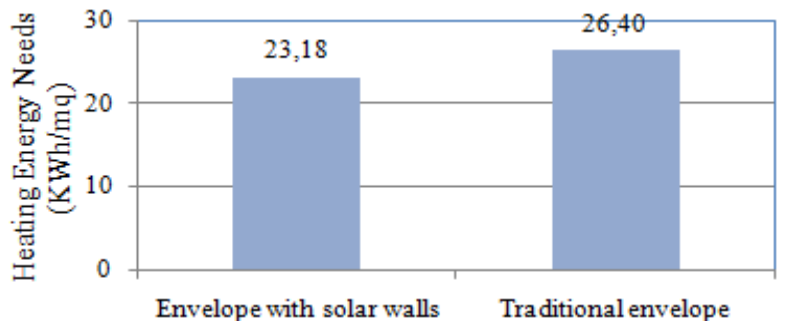

Fig. 15. Seasonal heating energy of building with different types of envelope.

The results of thermal comfort analysis in winter (Fig. 16) are very similar for the building with solar wall and with traditional wall because the influence of heating system is relevant in this season. However in the middle seasons solar walls' heat gains determine higher indoor air temperature and consequently higher PMV values. In these periods it could be necessary to shade solar walls to avoid overheating problems.

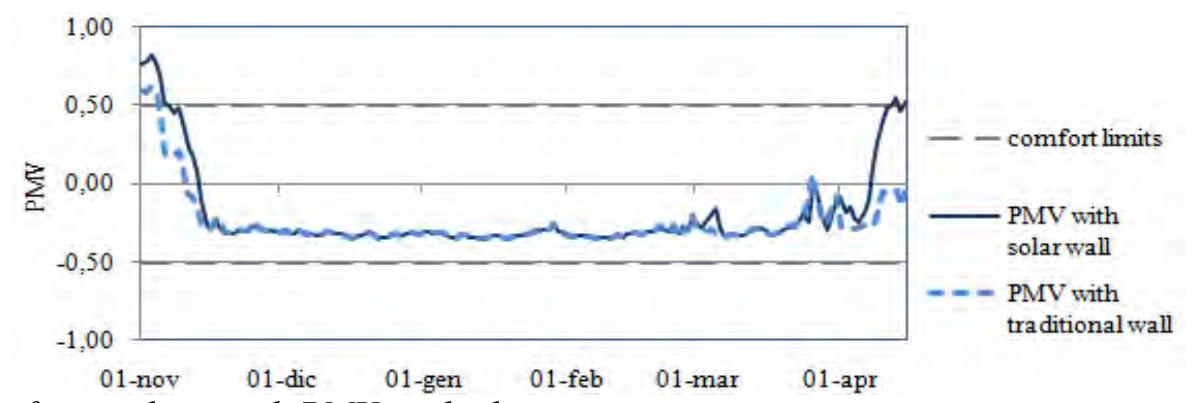

Fig. 16. Comfort analysis with PMV method in winter.

In summer the building with solar walls, shaded from solar radiation, has indoor comfort level comparable to the traditional one. The results of PMVe analysis for summer (Fig. 17) highlighted overheating problems for the hottest days, when PMVe exceeds the comfort superior limit of 0,5 for both the cases considered.

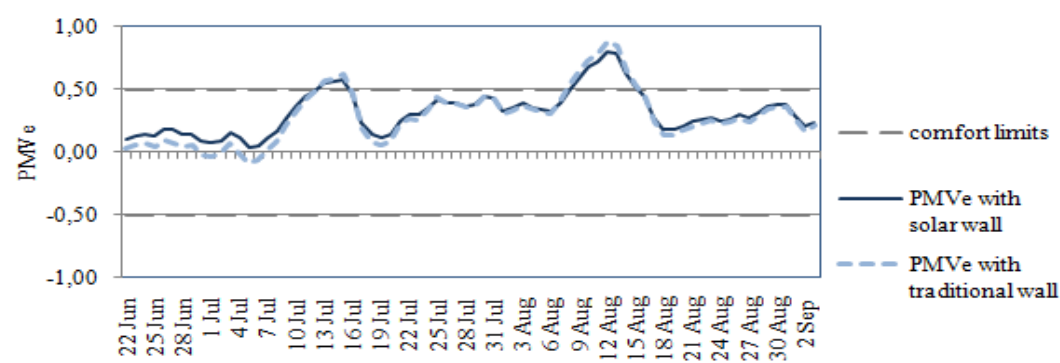

Fig. 17. Comfort analysis with PMVe method in summer.

\subsubsection{Optimization of solar walls}

Results of parametric analyses on the configuration of solar wall are in Fig. 18. The single variation of wall thickness from $40 \mathrm{~cm}$ to $30 \mathrm{~cm}$ (X1) increases energy needs; the single variations of external surface's absorbance (X2) or the type of glazing from single to double (X3) decrease energy needs. The type of glazing resulted to be the parameter with a greatest influence, with a reduction of $-4,28 \mathrm{kWh} / \mathrm{m}^{2}$ on energy needs.

The interactions between parameters are small, except the one between wall thickness and type of glazing. This implies that, even if the single effect of reducing wall thickness is disadvantageous, combining this variation with the variation of glazing from single to double 
has a beneficial effect. The best performance as obtained with a wall thickness of $30 \mathrm{~cm}$, absorbance 0,90 and double glasses.

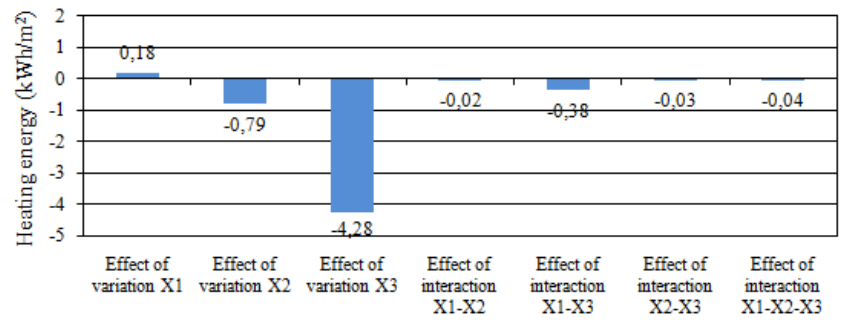

Fig. 18. Results of parametric analyses with level factorial plan.

\section{Conclusions}

An experimental and analytical study on the performances of solar walls in a residential building in central Italy was carried out. The study confirmed that solar wall is an efficient system in reducing energy needs for the heating season and assuring suitable comfort levels. Some problems of overheating emerged in summer in buildings with well-insulated envelope. This drawback can be reduced using adequate solar protections for solar walls; however we consider necessary further investigations on the behavior of the system in summer. Parametric analyses made it possible to compare different configurations of solar wall; the results may be used as design recommendation for solar walls.

\section{References}

[1] G. Gan, A parametric study of Trombe walls for passive cooling of buildings, Energy and buildings 27,1998 , pp. $37-43$.

[2] G. Gan, S. B. Riffat, A numerical study of solar chimney for natural ventilation of buildings with heat recovery, Applied Thermal Engineering 18, 1998, pp.1171-1187.

[3] V. H. Hernandez Gomez, et al., Design recommendations for heat discharge systems in walls, Applied Thermal Engineering 30, 2010, pp.1616 - 1620.

[4] H. Chan, S. B. Riffat, J. Zhu, Review of passive solar heating and cooling technologies, Renewable and Sustainable Energy Reviews 14, 2010, 781-789.

[5] L. Zalewski, S. Lassue, B. Duthoit, M. Butez, Study of solar walls - validating a simulation model, Building and Environment 37, 2002, pp. 109-121.

[6] A. Fernandez-Gonzalez, Analysis of the thermal performance and comfort conditions produced by five different passive solar heating strategies in the United States Midwest, Solar Energy 81, 2007, pp.581-593.

[7] F. Stazi, A solar prototype in a Mediterranean climate: reflections on project, use, results of the monitoring activities, calculations, Proceedings World Renewable Energy Congress WREC, Aberdeen, 2005.

[8] F. Stazi, C. Di Perna, C. Filiaci, A. Stazi, The solar wall in Italian climates, International Journal of Mathematical, Physical and Engineering Sciences 2, 2008, pp.86-94.

[9] P. G. Ellis, Development and validation of the unvented Trombe wall model in EnergyPlus. Master's Thesis, University of Illinois at Urbana-Champaign, 2003.

[10]P. O. Fanger, J. Toftum, Extension of the PMV model to non-air-conditioned buildings in warm climates, Energy and Buildings 34, 2002, pp.533-536. 